Sophisticated Voting on Competing Ballot Measures: Spatial Theory and Evidence

Paper submitted to the British Journal of Political Science

February, 2008

Author: David Hugh-Jones, Department of Government, University of Essex

Address: University of Essex

Tel: +447872188110

Email: dhughj@essex.ac.uk

Heartfelt thanks to Albert Weale, David Sanders, Peter Bloom, Thomas Pluemper, five anonymous reviewers and especially Hugh Ward for comments on earlier drafts. William Jacoby gave me useful statistical advice, as did Dean Lacy, Larry Bartels, Douglas Rivers, and others on the POLMETH mailing list. Catherine Hafer and Ruth Baldry taught me game theory. Susan Banducci, Steven Brams and the staff at UCSD library all helped me in different ways. More generally I would like to thank John Thompson and Elspeth Probyn. 


\title{
Sophisticated Voting on Competing Ballot Measures: Spatial Theory and Evidence
}

\author{
David Hugh-Jones
}

Are voters sophisticated? Rational choice theories of voting assume that they are. Students of voting behaviour are more doubtful. I examine voting in a particularly demanding setting: direct democratic elections in which two competing proposals are on the ballot. I develop a spatial model of voting and proposal qualification with competing proposals. If voters are naïve, then competing proposals can be used to block the direct democratic route to change. But if voters vote strategically, competing proposals can bring outcomes closer to the median voter. Examining voting intention data from California polls, I find evidence that some votes are cast strategically even in these demanding circumstances. However, the level of strategic voting appears to be affected by the tenor of the election campaign. 


\section{Introduction}

Direct democratic systems face a problem not found in pure representative democracies: what should the outcome be when voters simultaneously approve two or more contradictory measures? In many systems, the measure with most votes wins out. This rule offers any ballot proposal's opponents a powerful tactic: to qualify a "counter-proposal" on the same subject and draw support away from the original proposal, or split the electorate so that both proposals fail. For example, California's famous Proposition 13, which kick-started the latest wave of initiative usage in 1978, faced the more moderate Proposition 8 , sponsored by the state legislature; in 1988 Proposition 103 on auto insurance reform faced four different competitors; and Proposition 79, to provide prescription drugs for poorer Californians, competed with the industry-sponsored Proposition 78 in November 2005. These are some of the highest-profile and most expensive initiative campaigns in recent years: counter-proposals are an important part of California's direct democratic landscape, adding to an arsenal of tools that opponents of a direct democratic measure can use to prevent its being passed and implemented. ${ }^{1}$

When a pair of competing proposals are on the ballot, the voter faces a difficult choice. Even if she knows the content of each proposal, she must decide whether to vote for one, none or both. Suppose that the voter prefers both proposals to the status quo, but most prefers the original proposal. Voting for only the original proposal may help it to beat the counterproposal. But there is the risk that both proposals may fail. On the other hand, voting for both

1 See especially Elisabeth Gerber, Arthur Lupia, Mathew D. McCubbins, and D. Roderick Kiewiet, Stealing the Initiative: How State Government Responds to Direct Democracy

(New Jersey: Prentice Hall 2000). 
proposals increases the chance that the counter-proposal will pass, but also increases the chance that it will beat the original proposal. The optimal way to vote depends on the probabilities of being pivotal between the original proposal and the status quo, between the counter-proposal and the status quo, and between the two proposals. So, it depends on how others plan to vote.

The voting behaviour literature raises the question of whether voters will be able to achieve this level of sophistication. First of all, how will rationally ignorant voters find out the content of proposals? If they achieve this, how will they coordinate with other voters to make an optimal choice? To these challenges to voter competence, optimists may reply that cues and heuristics will help voters make the right decision without having to think too hard. ${ }^{2}$ If this account is correct, competing direct democratic proposals create a particularly demanding choice situation for voters. Direct democratic votes are often not very salient, so voters may pay them little attention and rely more than usual on heuristic rather than systematic information processing. Strategic voting on competing proposals may require voters to vote yes on both of two apparently opposed measures, which arguably requires more political knowledge and sophistication than the relatively simple task of voting for one's most preferred of the top two candidates in a multi-candidate election. The key heuristic of party identification is often unavailable in ballot initiative votes, because they may be proposed by any individual or group. (Party identification may be useful if proposals have been referred to the people by the legislature.) Worse, even if the ideology of the proposer is known to voters, in the case of competing proposals this cannot be mapped to the content of the proposal. A simple example will show why. First consider a voter with ideal point $\mathrm{V}$ facing a status quo

2 Paul M. Sniderman, Richard A. Brody, and Phillip E. Tetlock, Reasoning and Choice, Explorations in Political Psychology (Cambridge: Cambridge University Press 1991); Samuel L. Popkin, The Reasoning Voter: Communication and Persuasion in Presidential Campaigns (Chicago: University of Chicago Press 1991). 
SQ and an original proposal $P_{l}$, proposed by an interest group whose ideal point $\mathrm{G}$ is known to him. In this situation, the voter can at least infer which side of the status quo the proposal is. G will never propose $P_{l}$ on the opposite side to SQ from G: this could only make the group worse off. See Figure 1.

(Figure 1 about here.)

Now consider a pair of competing proposals, shown in Figure 2. Suppose that the voter already knows the location of $P_{l}$. A conservative group $\mathrm{C}$, on the opposite side of the status quo from the voter and the proposal, puts a counter-proposal on the ballot. It would like to propose and pass its own ideal point, but this may not be feasible. Instead it may have to propose a compromise $P_{2}$ which is worse for it than the status quo, but better than $P_{l}$. Now the link between the conservative group's ideal point $\mathrm{C}$, and its proposal location $P_{2}$, is broken: they may indeed be on opposite sides of the status quo.

(Figure 2 about here.)

For all these reasons, competing direct democratic proposals offer a hard test for theories of strategic voting. This paper has two components. In the theoretical component, I show the serious consequences if voters fail that test. For, even under the optimistic "complete information" assumption that voters have precise knowledge of the content of proposals, if voters are naïve, counter-proposals can be used to block all possibility of policy change via the direct democratic route. On the other hand, if voting is strategic, counter-proposals can actually benefit direct democracy by making the agenda-setting process more competitive.

My empirical tests then examine four sets of competing proposals in California. Using data 
from opinion polls close to the election, I find evidence for strategic voting in some elections. I hypothesize that voters' strategies are indeed influenced by cues from elites: when campaigns are highly polarized, strategic voting is less likely. Nevertheless, if enough voters can achieve sophisticated voting behaviour, the direct democratic process will not be blocked by counter-proposals.

The paper is organized as follows. The next section describes counter-proposals in more detail, and briefly reviews the literature on counter-initiatives and voter sophistication. In section 3 I develop a spatial model of counter-proposals, which treats interest groups as rational but allows various assumptions about voter behaviour. (The appendix contains formal proofs.) I find that if "naïve" voters support only their most preferred option, a counterproposal can split the voters and ensure that both proposals fail. But if voters are rational, the threat of the counter-proposal brings outcomes closer to the median voter. In section 4 these competing predictions are tested with polling data from California. The results show that at least some voters are sophisticated. However, the level of sophisticated behaviour varies between elections. Section 5 examines what drives this variation. Finally, I draw theoretical and practical conclusions.

\section{Counter-proposals in the literature}

As stated above, in a direct democracy voters may vote simultaneously for measures with conflicting provisions. There are different ways to resolve or prevent this. In Switzerland, when a popular initiative faces a counter-proposition from the legislature, votes are taken on both, and if both pass, only the one with most votes is implemented. Until 1987 voters could only vote yes on one out of the two proposals: support would often be split so that both failed. Since 1987 voters have been able to vote yes on both propositions and to choose one as their 
first preference if both pass. In the US, Washington State allows the legislature to offer an alternative to an initiative. Voters choose first whether they would prefer either of the two to the status quo, then choose one of the two measures; if a majority votes for change, then the most popular proposal passes.

Thirteen US states explicitly use the system explored in this paper. ${ }^{3}$ Their constitutions lay down that if the provisions of two simultaneously passed ballot proposals conflict, those of the proposal with more votes will take effect. This rule does not completely specify the system. The courts or constitution must also rule on what count as conflicting provisions. Narrow or broad interpretations of conflict are possible. As an example of the latter, the California Supreme Court has ruled that when proposals lay out different "comprehensive" schemes of regulation on the same topic, the proposals conflict. ${ }^{4}$ Some ballot proposals include specific language invalidating other measures on the same issue if those measures pass with fewer votes.

There is a small literature specifically on counter-proposals. Dubin, Kiewiet and Noussair develop a choice model for counter-proposals: rather than a full Nash equilibrium, they model

\footnotetext{
${ }^{3}$ Arizona, Arkansas, California, Colorado, Idaho, Massachussetts, Michigan, Missouri, Nebraska, Nevada, North Dakota, Ohio, Utah. Mississippi uses this system unless the counter-initiative is sponsored by the legislature, in which case the Washington State system is used. Oklahoma uses this system but specifies that if both measures fail but one gets more than a third of votes cast, it is voted on alone at the next election. See the list of state constitutions at http://www.iandrinstitute.org, downloaded December 2005.

${ }^{4}$ Supreme Court of California, Taxpayers to Limit Campaign Spending v. Fair Political Practices. Commission, 51 Cal.3d 744 . [No. S012016. Supreme Court of California. Nov 1, 1990.]
} 
a "first-order strategy" for groups of voters who assume that other groups will vote sincerely ${ }^{5}$. They find evidence for strategic voting by showing that aggregate support for a more moderate proposition sometimes decreases as support for change increases, because extremists prefer to avoid a compromise. Banducci provides the most comprehensive examination to date. ${ }^{6}$ As well as examining the effect of competing proposals on voter information, she examines voter choice over counter-proposals, and sees voting yes on both proposals as normally irrational. However, I show below that rational voters may vote "yes on both" in equilibrium. Banducci provides important evidence about voter behaviour in the presence of counter-proposals. Reversals of majority opinion during the campaign are more likely for competing sets of proposals, than for initiatives which face no counter-proposal; initiatives which face a counter-proposal are more expensive and more likely to fail. The influence of ideology on voting is strong for original initiatives but weaker for counterproposals, a finding supported by Bowler and Donovan in their examination of California's competing propositions 131 and $140^{7}$. Banducci explains this by suggesting that counterproposals are the subject of mixed messages from elites, who only support them in order to defeat the original initiative, and thus confuse voters. It might alternatively be that counterproposals get most support from the centre ground, so that the link between ideology and support is non-linear.

Counter-proposals get a similarly bad press in more general work. Dubois and Feeney, writing shortly after the 1990 California election, worry about the number of competing

\footnotetext{
${ }^{5}$ Jeffery A. Dubin, Roderick D. Kiewiet and Charles N. Noussair, "Voting on Growth Control Measures". Economics and Politics 4 (1992), 191-213

${ }^{6}$ Susan Banducci. "Counter-propositions”, unpublished $\mathrm{PhD}$ dissertation (University of California, Santa Barbara 1995)

${ }^{7}$ Shaun Bowler and Todd Donovan, Demanding Choices: Opinion, Voting and Direct

Democracy (Ann Arbor: University of Michigan Press 1998)
} 
proposals on the ballot, and recommend preventing proposals from changing the rules governing their own effect (as many counter-proposals do by including measures to override competing proposals). ${ }^{8}$ The California Commission on Campaign Finance Reform sees counter-proposals as "a tactic to confuse voters". ${ }^{9}$ Donovan, Bowler, McCuan and Fernandez categorize them as a tactic used by "narrow" interest groups competing against one another. ${ }^{10}$ Magleby sees counter-proposals as designed to confuse and fatigue voters, but also as compromises which move "part way towards the objective of the original initiative". ${ }^{11}$ On the other hand, some of the same authors recommend counter-proposals from the legislature as a way to moderate direct democracy's excesses. ${ }^{12}$ This paper moderates the negative view of counter-proposals, by offering a more nuanced theory. When voters are naïve, counterproposals do indeed split the electorate and frustrate the democratic will. If (some) voters can

\footnotetext{
${ }^{8}$ Philip L. Dubois and Floyd Feeney, "Improving the California Initiative Process: Options for Change.” (Berkeley: California Policy Seminar 1991)

${ }^{9}$ California Commission on Campaign Finance Reform, Democracy by Initiative: Shaping California's Fourth Branch of Government. (Los Angeles: Center for Responsive
} Government 1992)

${ }^{10}$ Todd Donovan, Shaun Bowler, David McCuan and Kenneth Fernandez, "Contending players and strategies: Opposition advantages in initiative elections" in Shaun Bowler, Todd Donovan and Caroline Tolbert, eds., Citizens as Legislators: Direct Democracy in the United States (Columbus: Ohio State University Press 1998)

${ }^{11}$ David Magleby, "Direct Legislation in the American States" in David Butler and Austin Ranney, eds., Referendums around the World: The Growing Use of Direct Democracy. (London: Macmillan 1994)

${ }^{12}$ e.g. Dubois and Floyd Feeney, "Improving the California Initiative Process"; California Commission on Campaign Finance Reform, Democracy by Initiative; also Richard Ellis, Democratic Delusions (Lawrence: University Press of Kansas 2002). 
make sophisticated voting choices, however, counter-initiatives can actually bring outcomes closer to the median voter.

To understand which of these outcomes occurs, therefore, we need to understand how voters actually make their minds up in these elections. Perhaps the best-known contribution to the literature on voting behaviour in this context is Lupia's claim that ignorant voters can use the support or opposition of known individuals or groups for a ballot proposition, to determine whether they should support it themselves, thus overcoming the lack of cues from partisanship or retrospective evaluation. ${ }^{13}$ Although Lupia's study examined voting on five competing insurance initiatives, his theory did not examine the strategic choice situation directly, instead focusing simply on whether less knowledgeable voters could emulate more knowledgeable ones. However, scholars within the voting behaviour tradition have sought heuristics that enable strategic voting more generally. Duch and Palmer suggest that charismatic major party leaders can act as a coordination device for strategic voting, while Forsythe et al. suggest that electoral history can do the same, a claim supported by Gschwend's analysis of German elections.$^{14}$ Neither history nor party leaders are available in

${ }^{13}$ Arthur Lupia, "Shortcuts Versus Encyclopedias: Information and Voting Behavior in California Insurance Reform Elections.” American Political Science Review 88:1 (1994), $63-76$

${ }^{14}$ Raymond M. Duch and Harvey D. Palmer, "Strategic Voting in Post-Communist Democracy?” British Journal of Political Science 32 (2002), 63-91; Robert Forsythe, Roger B. Myerson, Thomas A. Rietz and Robert J. Weber, "An experiment on coordination in multicandidate elections: The importance of polls and election histories." Social Choice and Welfare 10:3 (1993) 223-247; Thomas Gschwend "Ticket-splitting and strategic voting under mixed electoral rules: Evidence from Germany", 
direct democratic votes. This raises the question: can voters vote sophisticatedly on ballot proposals? The current article shows that at least some of them can. It also suggests that campaigns themselves can provide cues on how to vote, and the nature of these cues can explain when the electorate as a whole succeeds and fails to vote sophisticatedly.

When competing propositions are on the ballot, a voter may want one proposition to pass if the other fails, but to fail if the other passes. In other words, counter-propositions induce nonseparability in voter preferences over ballot results, even when preferences on the underlying policy dimension are separable. Lacy and Niou show that naïve voting with non-separable preferences can lead to universally disliked outcomes, and/or manipulation by an agendasetter. ${ }^{15}$ I confirm this result in a specific setting, but disagree with their resulting pessimism about direct democracy. Voting behaviour in elections need not be naïve: instead, the voting strategies adopted may depend on cues from political elites.

\section{The formal model}

Our model is as follows. The status quo is $S Q$. An interest group G puts proposition $P_{l}$ on the ballot. We treat the alternatives $S Q$ and $P_{l}$ as points on a line, and assume that voters know what the alternatives are, have an ideal policy point on the line, and prefer outcomes closer to that point (utility functions are symmetric and single-peaked over the real line). The interest group wants policy to be as high as possible. If counter-proposals are not possible, the highest

European Journal of Political Research 46:1 (2007), 1-23.

${ }^{15}$ Dean Lacy and Emerson M. S. Niou. “A Problem With Referendums”, Journal of

Theoretical Politics (2000) 12(1), 5-32 
policy they can achieve is determined by the median voter, whose ideal point is $M V$. Let $M V^{\prime}$ be the point as far away from $M V$ on the right as $S Q$ is on the left: the median voter is indifferent between $M V^{\prime}$ and $S Q$. If $P_{l}$ is to the right of $M V^{\prime}$, the median voter and the half of the electorate to her left will prefer $S Q$. So the highest proposal that will pass is located at $M V^{\prime}$. The interest group sponsors $P_{I}=M V^{\prime}$, and this is the outcome. ${ }^{16}$

To examine the effect of counter-proposals, we introduce a second, "conservative" interest group C, who may sponsor a counter-proposal $P_{2}$. See again figure 1 . The conservative group wants policy to be as far to the left as possible. (This is a simplification. All that is required is for C's ideal point to be to the left of Q and G's ideal point to be the right of MV'. Thus, counter-proposals from the legislature fit this pattern, if we can presume its ideal point to be at Q.) The conservative group decides whether to sponsor after learning G's decision. This fits the pattern of past counter-proposal campaigns. Both propositions are the same side of the status quo as the median voter. (Proposals on the other side of the status quo from the median voter would never pass, and so could not threaten a proposal that might pass.) Election returns translate into outcomes as follows, where $\mathrm{Y}^{*}$ indicates the proposition receiving more votes:

\begin{tabular}{ll|l}
$\boldsymbol{P}_{1}$ & $\boldsymbol{P}_{2}$ & Outcome \\
\hline $\mathrm{Y}^{*}$ & $\mathrm{Y}$ & $P_{I}$ \\
\hline $\mathrm{Y}$ & $\mathrm{N}$ & $P_{1}$ \\
\hline $\mathrm{Y}$ & $\mathrm{Y}^{*}$ & $P_{2}$ \\
\hline $\mathrm{N}$ & $\mathrm{Y}$ & $P_{2}$ \\
\hline $\mathrm{N}$ & $\mathrm{N}$ & $S Q$ \\
\hline
\end{tabular}

\footnotetext{
${ }^{16}$ This is the "setter model": see Thomas Romer and H. Rosenthal, "Bureaucrats Versus Voters: On the Political Economy of Resource Allocation by Direct Democracy", Quarterly Journal of Economics (1979) 93:563-587.
} 
I examine two models. In the first, voters are naïve: they vote only for the outcome they most prefer. In the second, voters are sophisticated and vote to maximize their utility. (Voters in both models are sincere, by Brams' definition that a sincere voter who votes for option X must also vote for all options she strictly prefers to $X .{ }^{17}$ ) An alternative model of naïve voting would assume that voters vote for any proposal they prefer to the status quo. Under this assumption, a $P_{2}$ placed just to the right of the status quo is guaranteed to beat $P_{l}$ : as it will be supported by a superset of the supporters of $P_{l}$ and so will pass with more votes. Thus the direct democratic route to substantive change is blocked ${ }^{18}$. This model does not resemble reality: empirically, as we shall see, double-yes voting is rare.

\section{Naïve voters}

If voters only vote for their preferred proposition, then change will be limited by the costs of the conservative group. The intuition is straightforward. So long as some voters prefer the staus quo to any change towards the median voter, the remaining voters can be split into two equal sized groups by an appropriately placed counter-proposal. As these groups each comprise less than half the electorate, both proposal and counter-proposal fail. The situation is shown in Figure 3.

(Figure 3 about here.)

Proposition 1: if voters are naïve, no change from the status quo occurs when counterproposals are possible.

${ }^{17}$ Steven Brams, "Strategic Information and Voting Behavior", Society (1982) 19:4-11

18 A formal proof is available on request. 
Proof: see the Appendix.

In short, if voters are naïve, counter-proposals frustrate substantive reform. If we assume that voters randomize between proposals that are located at the same point, then the conservative group can block change simply by placing $P_{2}=P_{1}$. Even if voters coordinate when faced with two identical proposals, any change can be blocked, although this might involve a counterproposal to the right of the original proposal.

\section{Sophisticated voters}

Possible preference schedules, over real world outcomes and election returns, are as follows, where $\succ$ means "strict preference" and $\sim$ means "indifference". We give voters with each preference schedule an arbitrary but convenient label. For example, "conservatives" rank the status quo $S Q$ above $P_{2}$ and $P_{2}$ above $P_{1}$; therefore they most prefer No on both proposals $(\mathrm{NN})$, followed by either Yes on the counter only (NY), or Yes on both with the counter gaining more votes $\left(\mathrm{YY}^{*}\right)$, both of which mean that $P_{2}$ is the outcome; their least preferred options are the two outcomes $\mathrm{YN}$ and $\mathrm{Y}^{*} \mathrm{Y}$ which lead to $P_{1}$.

\begin{tabular}{lcc}
\hline \multicolumn{1}{c}{ Label } & Outcome preferences & Ballot preferences \\
\hline "conservatives" & $S Q \succ P_{2} \succ P_{1}$ & $\mathrm{NN} \succ \mathrm{NY} \sim \mathrm{YY}^{*} \succ \mathrm{YN} \sim \mathrm{Y}^{*} \mathrm{Y}$ \\
\hline "moderates" & $P_{2} \succ S Q \succ P_{1}$ & $\mathrm{NY} \sim \mathrm{YY}^{*} \succ \mathrm{NN} \succ \mathrm{YN} \sim \mathrm{Y}^{*} \mathrm{Y}$ \\
\hline "progressives" & $P_{2} \succ P_{1} \succ S Q$ & $\mathrm{NY} \sim \mathrm{YY}^{*} \succ \mathrm{YN} \sim \mathrm{Y}^{*} \mathrm{Y} \succ \mathrm{NN}$ \\
\hline "radicals" & $P_{1} \succ P_{2} \succ S Q$ & $\mathrm{YN} \sim \mathrm{Y}^{*} \mathrm{Y} \succ \mathrm{NY} \sim \mathrm{YY}^{*} \succ \mathrm{NN}$ \\
\hline
\end{tabular}

Other schedules are ruled out by single-peakedness. Voting is straightforward ${ }^{19}$ only for

${ }^{19}$ In the sense of Robin Farquharson, Theory of Voting. (New Haven: Yale University Press 
moderates, who want $P_{2}$ to pass and $P_{1}$ to fail in all circumstances. Other voters' preferences are non-separable: for example, conservatives will want $P_{2}$ to beat $P_{1}$ if they expect a yes on $P_{1}$, but will want $P_{2}$ to fail if $P_{1}$ does so too. Figure 4 shows the intervals containing the ideal points of the four voter blocs.

(Figure 4 about here.)

I assume that voters in each of the four blocs coordinate as if they made up a single unitary actor. The idea behind this is that voters in each bloc take cues on how to vote from elites who share their preferences. For example, voters may take advice from newspapers, which regularly run editorials recommending a Yes or No vote on a particular proposals, or from bodies like the National Organization of Women or Americans for Democratic Action, which produce voter guides to the proposals on the ballot, or from elected politicians who come out for or against a particular proposal. Assuming that voters are individually rational would complicate the analysis without leading to substantially different results. ${ }^{20}$

The sophisticated voting game has multiple equilibria and is less intuitive than naive voting. However, its results are more optimistic. Voter sophistication prevents the conservative interest group from splitting the electorate. At the same time, the interest group G is constrained to propose $P_{1}$ closer to the median voter by the threat of a counter-proposal.

Proposition 2: when voters are sophisticated and counter-proposals are possible, the outcome of a direct democratic campaign will be strictly closer to the median voter's ideal

1969)

20 A model of individually rational voting demonstrating this is available from the author on request. 
point than the status quo.

Proof: see the Appendix.

The argument is best illustrated with a pair of examples. First, suppose that the original interest group proposes $P_{l}=M V$. Then, any counter-proposal to the left of $P_{l}$ will fail, as radicals - those who prefer $P_{1}$ to both $P_{2}$ and the status quo - form a majority, and can achieve their most favoured outcome by voting YN. On the other hand, suppose that $P_{I}=M V$, so that the median voter is indifferent between the proposal and the status quo. Then consider a counterproposal $P_{2}=M V$. Now, the conservative, moderate and progressive groups prefer $P_{2}$ to $P_{1}$, and these are a majority of the voters. There is then a voting equilibrium in which all three groups vote NY and $P_{2}$ passes, beating $P_{1}$. Neither of these examples show equilibrium behaviour by the interest groups: in equilibrium, the original interest group proposes $P_{l}$ to the right of the median voter, but not so far as to generate a successful counter-proposal.

If votes are cast sophisticatedly, then the threat of counter-proposals does not block substantive change by the initiative process. Instead, initiatives are moderated towards the median voter.

\section{Empirical tests}

My models generate predictions about counter-proposal outcomes. Strictly, both models predict no counter-proposals in equilibrium. This unrealistic prediction is driven by the assumption of complete information. If we allow that interest groups may be mistaken about voter opinion, then some counter-proposals will occur. The naïve model then says that the counter-proposal can usually be written to cause both competing proposals to fail. The 
sophisticated model says that the counter-proposal will not make both proposals fail (unless both interest groups have completely misestimated the voters' preferences) but will normally pass with more votes, or pass while the original proposal fails. Table 2 collates the results of all pairs of competing proposals in California since the introduction of the initiative.

(Table 2 about here.)

Clearly, neither naïve voting nor sophisticated voting explains all the results. Although the modal outcome is that both competing initiatives failed (as naïve voting would predict), more than half of the cases show one or other initiative succeeding. In addition, there are three cases in which both initiatives got a majority of the vote. This clearly could not happen unless at least some voters were voting yes on both initiatives. So there is some prima facie evidence of sophisticated voting from the macro-level data. On the other hand, perhaps voter ignorance, rather than sophistication, explains YY voting: maybe YY voters simply did not realise that the relevant ballot measures were in conflict, or did not understand the consequences if both passed. There may also have been competing proposals which do not fit our model - for example, if rival proposals for change are put forward by two groups who favour different degrees of reform, or groups with different preferences in a multidimensional issue space. One important issue is that the court decision giving a broad interpretation to "competing" proposals was given in 1990. Arguably, before the ruling, the legal situation was unclear and voters may have been uncertain about the outcome if both proposals passed. However, as stated, some initiatives contained language explicitly invalidating their rivals wholesale if they passed with more votes (examples include Proposition 1a in 1968 and Proposition 104 in 1988).

To detect sophisticated voting, I therefore examine individual voting intention data in a subset of proposal pairs which clearly match the model conditions. The sophisticated model allows 
multiple equilibria. For testing, we assume that when a group could vote in different ways without affecting the outcome, members of the group will vote in any undominated way, as there is no payoff to effort spent on coordination. Predicted voting patterns from the voting game are shown in Table 3.

(Table 3 about here.)

Sophisticated models predict YY voting by groups of voters defined by the underlying policy dimension: either a group of voters in the middle of the policy spectrum, or all voters to the right of some cutpoint. The naïve model predicts no YY voting. However, if some voters are unaware that proposals are competing, then of this uninformed group, more extreme voters will vote YY. Thus, on this slight extension to the naïve theory, YY votes should be found among more extreme and less informed voters. On the sophisticated theory, voters' levels of information should not be relevant; in some equilibria, more extreme voters vote YY, while in others, moderate voters vote YY. To sum up: if YY voters are more moderate than YN voters, then this is evidence against naïve voting. If YY voters are less informed than YN voters, this is evidence against sophisticated voting. If YY voters are more extreme than YN voters, this is compatible with either theory.

I select contests in which (1) voters are likely to have known the consequences of both initiatives passing - thus, contests after the 1990 court decision, or in which one or more proposal contained explicit language invalidating its rivals; (2) the contest clearly fits the model of one proposal's supporters aiming for policy change while the other group would ideally prefer no change at all; and (3) we have reasonably adequate data on underlying policy preferences. The chosen contests are listed below in Table 4 .

(Table 4 about here.) 
In 1988, Proposition 104 contained language invalidating other propositions on auto insurance if they passed with fewer votes (including Proposition 103). In the 1990 general election, a VRS exit poll with a large sample size allows us to find significant predictors of voting behaviour on two rival initiatives relating to term limits. In 1996, the Field poll asked respondents' opinions of Ralph Nader, backer of Proposition 216, and about support for government intervention more generally. In 2005, only demographics are available.

For all the regressions I used demographics as independent variables, including ethnicity, gender, income, education, religion and age, and where possible employment, unionization, home ownership and marital status. Each of these demographics has been found to predict votes in some, though not all, initiative elections. ${ }^{21}$ I also always included party allegiance and liberal-conservative ideology, which are known to be good predictors of ballot measure voting. ${ }^{22}$ Where possible, I also included measures for support for change on the proposals' topic. In 1988, I included support for two other ballot measures that were likely to be linked to support for government intervention: a proposal to establish a fund for homelessness and to restore funding for Cal-OSHA, the state's occupational safety and health plan. In the 1990 general election, I expected religious attendance, Protestantism, and concern over political

${ }^{21}$ Regina P. Branton, "Examining Individual-Level Voting Behavior on State Ballot Propositions”, Political Research Quarterly 2003, 56(3):367-377; Zoltan L. Hajnal, Elisabeth R. Gerber and Hugh Louch, "Minorities and Direct Legislation: Evidence from California Ballot Proposition Elections”, Journal of Politics 2002, 64(1):154-177; Shaun Bowler and Todd Donovan, op. cit.

22 Daniel A. Smith and Caroline J. Tolbert, "The Initiative to Party: Partisanship and Ballot Initiatives in California", Party Politics Quarterly 2001, 7(6):739-757; Regina P. Branton, op. cit.; Susan Banducci, "Searching for ideological consistency in direct legislation voting", in Shaun Bowler, Todd Donovan and Caroline Tolbert, op. cit. 
ethics (measured by belief that ethics mattered in the choice of state governor) to be predictors, as well as residence in a state seat which was uncontested, and in an uncontested seat occupied by someone of the "opposite" party to the respondent. I expected support for Pete Wilson, who had come out in favour of term limits, to predict support for change; similarly, as President Bush had supported term limits, I expected this to be relevant. In 1996, approval of Ralph Nader was expected to predict support for the original Proposition 216, sponsored by him; I also expected general support for government intervention to predict support for Proposition 216, as the proposition increased regulation of healthcare providers and imposed extra taxes.

\section{Results}

To explore whether YY voting can be predicted by underlying preference, I first run a set of logit regressions on the vote on the original proposal. ${ }^{23}$ Theories of naïve and sophisticated voting agree that voters to the right of some cutpoint vote Yes. The independent variables, multiplied by their estimated slopes, are the best linear predictor of the logged odds of a Yes vote, and thus provide a rough measure of underlying preference. I then plot voting patterns against this predicted probability. Both theories predict that NY voting should be related to ideology, usually in a non-linear way: conservatives vote $\mathrm{NN}$ and radicals vote $\mathrm{Y}$ on the first initiative, while those in the middle are more likely to vote NY. Both theories also predict that YY voting should be related to ideology: naïve voting predicts a positive relationship as uninformed extremists vote YY instead of YN; sophisticated voting predicts either a positive relationship or a non-linear relationship in which relatively centrist voters choose YY while extremists choose YN. Figure 5-Figure 7 divide voters into quintiles by their predicted probability of a Yes vote on the original proposition, and show the actual voting patterns in

23 Full results of these regressions are available from the author on request. 
each quintile.

(Figure 5-Figure 7 about here.)

The pictures show a clear relationship between YY voting and predicted probability of voting yes on the original proposal - unsurprisingly, as YY voters helped generate the predicted probabilities in the original regression. More interestingly, in the case of Propositions 131 and 140 , the ratio of YN to YY voting increases with the predicted probability. That is, among Yes voters on the original proposal, those with higher predicted probabilities of voting Yes on the original, were more likely to vote No on the counter-proposal. This is what would happen in a sophisticated equilibrium where more moderate voters were voting YY while more extreme voters chose YN. The same is true for Propositions 78 and 79 in 2005. In 1996, however, the reverse holds: more extreme voters are relatively more likely to choose YY than YN. The pattern in 1998 for Propositions 103 and 104 is less clear. It seems that in some cases at least, moderates are voting YY as the sophisticated voting theory would predict.

For a more formal test, I run a second round of logistic regressions, this time including only voters who voted Yes on the original proposal. The dependent variable is vote on the counterproposal: in other words, we are comparing $\mathrm{YY}$ voters to $\mathrm{YN}$ voters. As an independent variable, I include the predicted logged odds of voting Yes on the original proposal. This, again, gives a rough measure of underlying ideological position. I also include variables measuring the voter's levels of information about the proposals and interest in them. Naïve voting predicts that ideological position should be positively related to voting Yes on the counter-proposal, and negatively related to levels of interest and information. Sophisticated voting predicts that ideological position may be positively or negatively related to voting Yes on the counter; interest and information should not be significant. 
Results are reported in Table 5. There is some evidence to support both naïve and sophisticated models. In 1988 and 2005, voting YY was clearly linked to lack of information. (No measure of voter information was available in 1990.) On the other hand, in 1990 and 2005, voting YY was negatively correlated with our measure of the voter's ideal point: in other words, among those who voted Yes on the original proposal, more centrist voters were more likely to vote Yes on the counter, as the sophisticated voting model predicts.

(Table 5 about here.)

The simplest interpretation is that in the real world, some YY voters are unaware of the strategic situation, while others are deliberately choosing to support both measures against the status quo. Also, the numbers of each kind of voters varies in different elections.

\section{Heuristics for sophistication}

As not all initiatives are defeated by counter-initiatives, even when they face determined and organized opposition, the naive model of voting cannot capture the whole truth about counterproposals. On the other hand, as pairs of competing proposals often do fail, it seems likely that counter-proposals do sometimes succeed in splitting the voters. The data support a mixed interpretation in which there are some of each kind of voters. This raises the question: what determines whether voters act naively or strategically? In the absence of cues from past performance, electoral history or party allegiance, one possible source of information is the campaigns themselves. For example, in the 2005 vote on competing healthcare initiatives, the website supporting Proposition 79 contained prominent pages attacking Proposition 78, while the ballot pamphlet's supporters of Proposition 78 were also the opponents of Proposition 79, and advertisements were aired supporting 78 and simultaneously opposing 79 . Thus, the two propositions were presented to voters by both sides as opposites. Both failed. I suggest that voters accepted the frame proposed by both sides in the campaign, in which initiatives were 
seen as mutually opposed. Within this frame, voting YY made no sense: to support 79 was to be against 79 , and vice versa.

By contrast, consider Propositions 5 and 6 in 1982. Both of these banned inheritance tax. Although technically competing initiatives, they do not fit my model, as backers of both propositions sincerely wanted to abolish inheritance taxes. (Perhaps ego rents explain the duplication of effort in running two campaigns.) Indeed, the propositions were substantively identical, and in the ballot pamphlet, backers of Proposition 5 urged voters to vote Yes on 6 as well. The naive voters modelled above would have voted for one or the other and could at best have coordinated on one proposal. In fact, both passed handily.

To test the theory that voters take cues from the oppositional or mutually supportive nature of the campaign, I examine the effect of having viewed television advertisements for Propositions 78 or 79 on vote choice. If the campaigns encouraged voters to view proposals as mutually exclusive and opposing, then voters who had seen campaign advertising on television would be more likely to vote either YN or NY, and less likely to vote YY, than those who had not. Figure 9 shows the simple bivariate relationship between vote and advertisement exposure.

(Figure 9 about here.)

As expected, those who had seen the TV advertisement were more likely to vote either YN or NY. On the face of it, the TV ads (overwhelmingly funded by the pro-78/anti-79 camp) worked by converting YY voters into YN voters. A simple logit regression, with dependent variable "vote intention NY or YN", and controlling for awareness of the proposition, knowledge about the backers of each proposition, and education levels shows the coefficient on exposure to the TV ads positive and significant as expected, (p-value $=0.033$; model Nagelkerke $\mathrm{R}^{2}=.116$ ). Coefficients for knowledge about the backers of each proposition and awareness of the proposition were also positive and significant. Although data limitations prevent a more in-depth investigation into the causes of naive voting, there is reason to 
believe that at least in this case, the campaign polarized voters.

Supporters of the counter-proposal who seek to block all change have an incentive to polarize the campaign, but why do supporters of the original proposal fall into this trap? There are many possible reasons, though they are beyond the scope of the formal model. Being associated with a successful initiative may bring ego or reputational benefits. The initiative itself may reward its backers directly, perhaps by creating bureaucratic positions which they are likely to fill. Lastly, backers of the original proposal may be optimistic about its chances of winning and may therefore weigh the advantage of winning with their more radical proposal more highly compared to the benefit of getting at least some change if the counterproposal passes.

\section{Conclusion}

Most direct democratic elections are straightforward: voters need only decide whether they prefer a proposed change to the status quo. Counter-proposals, on the other hand, offer a demanding test of voter sophistication. Voters must gauge their preferences over competing proposals without the usual cues of party affiliation, and without being able to infer the content of a proposal from the preferences of its backers. They must also coordinate with other voters to translate their preferences into outcomes, for example by taking advice on how to vote from the media or from independent organizations such as the National Organization of Women. Given the obstacles they face, it is not surprising that sometimes, voters fail to coordinate and conservative groups succeed in splitting their opponents. But as voters regularly pass initiatives against organized and well-funded opposition, they cannot always fail at this task. Indeed, my analysis finds that at least some voters make sophisticated tactical choices in votes on competing ballot measures. However, this sophistication is not achieved unaided. The nature of the campaign mediates vote choice and polarized campaigns can push 
voters towards the naïve voting paradigm in which competing proposals are seen purely as rivals. Theoretically, this opens up the interesting question of how voter sophistication is enabled by political campaigning. Future work could develop models for this process. Practically, it should assuage the worry of Lacy and Niou (2000) that voters will be unable to cope when issues are linked. It also suggests that counter-proposals may not always deserve their bad press. They have the potential to confuse and divide voters. But if the circumstances are right, they can also offer reasonable compromises. Policy-makers should consider ways of explaining the voting situation better, to avoid manipulation by interest groups. For example, in California's ballot pamphlets, the Legislative Analyst could explicity discuss groups of competing initiatives together and explain how votes translate into outcomes. 


\section{Appendix: formal proofs}

\section{The model}

$R G$ and $C G$ are the radical and conservative group. The game proceeds as follows: $R G$ decides whether or not to submit a proposal at $P_{1} \in \mathbf{R}$ (i.e. on the real number line). If $R G$ makes a proposal, $C G$ decides whether or not to submit a counter-proposal at $P_{2} \in \mathbf{R}$. If there is a proposal, the voters vote. If there is one proposal the outcome is decided by majority rule, with $P_{1}$ beating the status quo $S Q=0$ if there is an even split. If there are two proposals, the outcome is $S Q$ if neither gain $50 \%$ of the electorate, $P_{l}\left(P_{2}\right)$ if only $P_{l}\left(P_{2}\right)$ gets $50 \%$ or more votes, and whichever of $P_{1}$ or $P_{2}$ gets more votes if both get $50 \%$ or more. If both have equal majorities, $P_{2}$ is the outcome.

Call the outcome $W \in \mathbf{R}$. Then utility for $R G$ is $U_{R G}=W$. Similarly, $C G^{\prime}$ s utility function is $U_{C G}=-W$. (It would make no difference if $C G$ had an ideal point lower than the status quo, or if $R G$ had an ideal point above $M V^{\prime}$.) For both groups, we ignore obviously dominated choices such as $P_{1}<S Q$ or $P_{2}>P_{1}$. We also assume that if either group cannot improve its utility by passing a proposal, it does not submit one.

Voters have ideal points distributed over the real line, which are common knowledge. Voter utility declines symmetrically and strictly from the voter's ideal point. Thus for a voter with ideal point $X$ and utility function $\mathrm{U}(),.|A-X|>|B-X|$ if and only if $\mathrm{U}(A)<\mathrm{U}(B)$. For simplicity, we assume a continuous distribution of voter ideal points with a density function which is strictly positive at all points of the real line, i.e. there are some voters everywhere. (It would make no difference if the distribution was positive only at an interval strictly containing 
$\left.\left[S Q, M V^{\prime}\right].\right)$ Call $\mathrm{N}(a, b)$ the proportion of voters in the interval $[a, b] . M V$ is the median voter ideal point: $\mathrm{N}(-\infty, M V)=1 / 2$. We assume without loss of generality that $M V>S Q=0 . M V^{\prime}$ is the median voter's indifference point to the status quo: $M V^{\prime}=2 M V$.

Individual voters are not players, as their choices are not strategic. Instead we model two separate assumptions.

\section{Naïve voters}

In this case, for any voter $V$ with ideal point $X, V$ votes for $P_{i}$ if and only if $\mathrm{U}_{V}\left(P_{i}\right) \geq \mathrm{U}_{V}(S Q)$ and $\mathrm{U}_{V}\left(P_{i}\right)>\mathrm{U}_{V}\left(P_{j}\right), i \in\{1,2\}, j=3-i$.

Proposition 1: if voters are naïve, no change from the status quo occurs when counterproposals are possible.

Proof: Suppose that $P_{l}$ will pass if unopposed. Thus $P_{l} \leq M V^{\prime}$. (If $P_{l}>M V^{\prime}$, then the median voter, and a fortiori the half of the electorate to the left of $M V$, will be closer to $S Q$ than $P_{l}$; furthermore as there are voters with ideal points everywhere along the line, $\mathrm{N}\left(M V,\left(S Q+P_{l}\right.\right.$ )/2) $>0$ and these voters are also closer to $S Q$ than $P_{l}$, giving a strict majority in favour of $S Q$.

Let $M V S$ be the ideal point of the median voter in the subgroup of voters to the right of $S Q$, so that $\mathrm{N}(S Q, M V S)=\mathrm{N}(M V S, \infty)$. Note that as $\mathrm{N}(-\infty, S Q)>0, M V S>M V$, and as $\mathrm{N}(M V, M V S)>$ $0, \mathrm{~N}(M V S, \infty)<\mathrm{N}(M V, \infty)=1 / 2$.

Suppose $P_{1}=M V S$. Then choose $P_{2}=P_{l}$. If so, by our conditions for voting, neither 
proposition gathers any votes. (Alternatively, if half the voters in $(S Q, \infty)$ were to vote for each proposition, then by our electoral rules both would fail. Even if voters could coordinate on a proposition in this case, a $P_{2}$ arbitrarily close to $P_{I}$ would ensure that both failed as $\left.\mathrm{N}\left(P_{1}+P_{2} / 2, \infty\right) \rightarrow \mathrm{N}(M V S, \infty)<1 / 2.\right)$

Suppose $P_{1} \neq M V S$. Choose $P_{2}$ such that $\left|P_{2}-M V S\right|=\left|P_{1}-M V S\right|$ and $P_{2} \neq P_{1}$. Either $P_{2}>M V S>$ $P_{l}$, in which case $P_{2}>S Q$, or $P_{2}<M V S<P_{l}$. Then, as in the main text: $P_{l} \leq M V^{\prime}=M V+$ $(M V-S Q)=2 M V-S Q ;$ if $P_{2}<P_{1}$, then $P_{2}=M V S-\left(P_{1}-M V S\right)=2 M V \mathrm{~S}-P_{1}$; hence $P_{2} \geq$ $2 M V \mathrm{~S}-(2 M V-S Q)=2(M V S-M V)+S Q$, and as $M V S>M V, P_{2}>S Q$.

Let $P_{L}$ be $\min \left(P_{1}, P_{2}\right)$ and $P_{H}$ be $\max \left(P_{1}, P_{2}\right)$. Only voters with ideal points in $(M V S, \infty)$ vote for $P_{H}$ and as $\mathrm{N}(M V S, \infty)<1 / 2, P_{H}$ fails. Only voters in $\left(\left(S Q+P_{L}\right) / 2, P_{L}\right)$ vote for $P_{L}$ and as $\mathrm{N}\left(\left(S Q+P_{L}\right) / 2, P_{L}\right)<\mathrm{N}(S Q, M V S)=\mathrm{N}(M V S, \infty)<1 / 2, P_{L}$ also fails. Thus the outcome is $S Q$.

As any $P_{1}>S Q$ will result in a counter-proposal splitting the voters and ensuring $S Q$ is the result, neither group submits a proposal and $S Q$ remains in place. QED.

\section{Sophisticated voters}

In the case of sophisticated bloc voting, the four blocs of voters who share ordinal preferences over outcomes coordinate their votes as unitary actors. Let $c=N(-\infty,(S Q+P 2) / 2)$, $m=N((S Q+P 2) / 2,(S Q+P 1) / 2), p=N((S Q+P 1) / 2,(P 1+P 2) / 2)$ and $r=N((P 1+P 2) / 2, \infty)$ denote the number of voters in each bloc.

Proposition 2: when voters are sophisticated and counter-proposals are possible, the outcome of a direct democratic campaign will be strictly closer to the median voter's ideal 
point than the status quo.

Proof: Each bloc has four strategies (YY, YN, NY and NN). This complicates the outcome space. We simplify as follows: first, if any bloc contains more than half of the electorate, it simply votes for its most preferred outcome. Second, voting for a proposition always makes it more likely to pass, and more likely to beat any other proposition. Therefore if a bloc's preferences over a proposition's passing are not dependent on the outcome of the vote on the other proposition, it always makes sense to vote accordingly. (Other strategies are weakly dominated.) In particular, moderates always vote NY. Other groups have the following nondominated strategy sets:

\begin{tabular}{lc}
\hline conservatives & $\mathrm{NY}, \mathrm{NN}$ \\
\hline progressives & $\mathrm{YN}, \mathrm{YY}$ \\
\hline radicals & $\mathrm{YN}, \mathrm{YY}$
\end{tabular}

Finally, if $m+p \geq c+r$, the outcome is $P_{2}$ : moderates will always vote NY, so progressives can achieve $P_{2}$, their preferred outcome, by voting NY as well, regardless of other groups.

We are now left with $2 \times 2 \times 2=8$ possible strategy profiles, and with a limited subset of population profiles such that any 3 groups will always beat the remaining group, and $c+r>$ $m+p$. The three possible resulting games are shown separately in Table 1, with Nash equilibria shaded.

(Table 1 about here.)

The outcomes are fairly simple: $P_{2}$ wins if the radicals on their own do not outweigh conservatives and moderates. If radicals outweigh conservatives and moderates $(r>c+m)$, 
then both $P_{1}$ and $P_{2}$ are Nash outcomes, but only $P_{l}$ remains after iterated elimination of weakly dominated strategies. (Eliminate conservatives' NY, then progressives' NY and finally radicals' YN. No other order of elimination leads to a different outcome.) This prediction depends on conservatives preferring a strategy based on the potential outcome $S Q$, which never occurs in equilibrium. It is perhaps more realistic to view the different Nash equilibria as the result of different coalitions of voting blocs: a moderate-progressive coalition leads to $P_{2}$ while a progressive-radical coalition leads to $P_{1}$. Suppose $P_{2}$ is the outcome when $r>c+m$. Then, as $P_{2}$ will pass whenever radicals are less than a majority, any $P_{1}>M V$ will be vulnerable to a successful counter-proposal $P_{2}=M V-\left(P_{1}-M V\right)+\varepsilon<M V$, while $P_{1}=M V$ will pass. Thus, RG will propose $P_{I}=M V$ and the proposition holds.

Suppose on the other hand that $P_{l}$ is the result when $r>c+m$. By continuity of the distribution of voters, we have that $c, m, p$ and $r$ are continuous in the locations of $P_{1}$ and $P_{2}$ so long as $S Q<P_{1}<P_{2}$.

Suppose $P_{l}=M V^{\prime}$. Then, $c+m=1 / 2$. Thus, any $P_{2}>S Q$ will ensure $r=N\left(\left(P_{1}+P_{2}\right) / 2, \infty\right)<N(M V$, $\infty)=1 / 2$, hence $r<c+m$ so that $P_{2}$ passes. Suppose $P_{1}=M V$. Then, for any $P_{2}<P_{1}, \mathrm{r} r=$ $N\left(\left(P_{1}+P_{2}\right) / 2, \infty\right)>N(M V, \infty)=1 / 2$ and so $P_{I}$ will pass. By continuity of $c, m, p$ and $r$, there must be some largest $P_{1} \in\left(M V, M V^{\prime}\right)$ such that no $P_{2}<P_{1}$ will pass. Formally, define $f\left(P_{2} ; P_{l}\right)=\max _{\{}\{c+m-r, m+p-c-r\}$ for $S Q<P_{2}<P_{l}$ and $f\left(S Q ; P_{l}\right)=\lim _{x \rightarrow S Q} f\left(x ; P_{l}\right)$ and $f\left(P_{l} ; P_{l}\right)=\lim$ ${ }_{x \rightarrow P I} f\left(x ; P_{l}\right)$, these limits existing by continuity of $f$ in $\left(S Q, P_{l}\right)$. Note that $\mathrm{P}_{2}$ is passable if and only if $\mathrm{f}\left(\mathrm{P}_{2} ; \mathrm{P}_{1}\right)>0$. Then $f$ is continuous on the closed interval $\left[S Q, P_{l}\right]$ and attains a maximum thereon by Weierstrass. Let $g(P 1)=\max _{S Q \leq P 2 \leq P 1} f\left(P_{2} ; P_{1}\right)$. By Berge's maximum theorem, $g$ is also continuous. I showed above that $g(M V)<0$ and $g\left(M V^{\prime}\right)>0$. Thus $g\left(P_{l}\right)=0$ for some values of $P_{l}$ strictly between $M V$ and $M V$. the set $\left\{P_{l}: g\left(P_{l}\right)=0\right\}$ is closed by continuity of $g$ and bounded, and therefore has a largest element. Call this element $P_{1} *$. For any $P_{1}>P_{1}^{*}$, there is some $P_{2}$ such that $f\left(P_{2} ; P_{1}\right)>0$; by continuity of $f$ this can always be made to be a $P_{2}$ strictly 
between $S Q$ and $P_{l}$.

To show that the radical group will choose $P_{1}^{*}$, we need to show that no $P_{1}>P_{1} *$ will generate a counter-proposal $\mathrm{P}_{2}>P_{1} *$. (By definition of $P_{1} *$ no $P_{1}>P_{1} *$ will pass on its own.) CG will propose the leftmost counter-proposal that passes, if there is one. For any $P_{1}>P_{1}{ }^{*}$, suppose that this leftmost $P_{2}>P_{1}{ }^{*}$. But by definition of $P_{1}{ }^{*}$, we have that for $P_{1}{ }^{\prime}=P_{1}{ }^{*}+\varepsilon$ where $\varepsilon>0$, hence in particular $P_{1}^{\prime}<P_{2}$, there is a $P_{2}^{\prime}<P_{1}^{\prime}$ with $f\left(P_{2}^{\prime} ; P_{1}^{\prime}\right)>0$. Furthermore, it is easy to see that $\mathrm{f}$ is weakly increasing in its $P_{1}$ argument. Thus $f\left(P_{2}{ }^{\prime} ; P_{1}\right)>0$ but as $P_{2}{ }^{\prime}<P_{1}{ }^{\prime}<P_{2}$ this contradicts the claim that $P_{2}$ is the leftmost passable counterproposal.

Thus in equilibrium the radical group chooses $P_{l} * \in\left(M V, M V^{\prime}\right)$ and this passes without generating a counter-initiative. This proves our claim as $P_{1} *$ is closer to $M V$ than $S Q$ is. QED. 


\section{Bibliography}

Banducci, Susan (1995). “Counter-propositions.” Unpublished PhD dissertation. University of California, Santa Barbara

Bowler, Shaun and Todd Donovan (1998). Demanding Choices: Opinion, Voting and Direct Democracy. Ann Arbor: University of Michigan Press

Bowler, Shaun, Todd Donovan and Caroline Tolbert (1998). Citizens as Legislators: Direct Democracy in the United States. Ohio: Ohio State University Press

Brams, Steven (1982). "Strategic Information and Voting Behavior." Society 19:4-11

Branton, Regina P. (2003). "Examining Individual-Level Voting Behavior on State Ballot

Propositions". Political Research Quarterly 56(3):367-377

California Commission on Campaign Finance Reform (1992). Democracy by Initiative:

Shaping California's Fourth Branch of Government. Los Angeles: Center for Responsive

Government

Dubin, Jeffery A., Roderick D. Kiewiet and Charles N. Noussair (1992). "Voting on Growth

Control Measures". Economics and Politics 4:191-213

Dubois, Philip L. and Floyd Feeney (1991). "Improving the California Initiative Process:

Options for Change.” Berkeley: California Policy Seminar

Duch, Raymond M. and Harvey D. Palmer (2002). "Strategic Voting in Post-Communist

Democracy?” British Journal of Political Science 32:63-91

Ellis, Richard (2002). Democratic Delusions. Lawrence: University Press of Kansas

Farquharson, R. (1969). Theory of Voting. New Haven: Yale University Press

Field Institute (1978). "Field Poll 78.06”. California. Distributed by UCData, San Diego.

Field Institute (1988). “Field Poll 88.07”. California. Distributed by UCData, San Diego.

Fiorina, Morris (1990). "Information and Rationality in Elections",

in John Ferejohn and James Kuklinski, eds., Information and Democratic Processes. Urbana: 
University of Illinois Press

Forsythe, Robert, Roger B. Myerson, Thomas A. Rietz and Robert J. Weber (1993). “An experiment on coordination in multi-candidate elections: The importance of polls and election histories." Social Choice and Welfare 10(3):223-247

Gschwend, Thomas (2007). "Ticket-splitting and strategic voting under mixed electoral rules: Evidence from Germany.” European Journal of Political Research 46(1):1-23

Hajnal, Zoltan L., Elisabeth R. Gerber and Hugh Louch (2002). "Minorities and Direct Legislation: Evidence from California Ballot Proposition Elections”. Journal of Politics 64(1):154-177

Initiative and Referendum Institute (2005). List of state constitutions. Downloaded from http://www.iandrinstitute.org, December 2005

Lacy, Dean and Emerson M. S. Niou (2000). “A Problem With Referendums”. Journal of Theoretical Politics 12(1):5-32

Lupia, Arthur (1994). “Shortcuts Versus Encyclopedias: Information and Voting Behavior in California Insurance Reform Elections.” American Political Science Review 88(1):63-76 Lupia, Arthur, Matthew D. McCubbins and Samuel Popkin (2000). Elements of Reason: Cognition, Choice and the Bounds of Rationality. New York: Cambridge University Press Magleby, David (1994). "Direct Legislation in the American States" in Butler, David and Austin Ranney, eds., Referendums around the World: The Growing Use of Direct Democracy. London: Macmillan

Popkin, Samuel L. (1991). The Reasoning Voter: Communication and Persuasion in Presidential Campaigns. Chicago: University of Chicago Press.

Romer, T. and H. Rosenthal (1979). "Bureaucrats Versus Voters: On the Political Economy of Resource Allocation by Direct Democracy.” Quarterly Journal of Economics 93:563-587 Smith, Daniel A. and Caroline J. Tolbert (2001). "The Initiative to Party: Partisanship and Ballot Initiatives in California.” Party Politics Quarterly 7(6):739-757

Sniderman, Paul M., Richard A. Brody, and Phillip E. Tetlock (1991). Reasoning and Choice, 
Explorations in Political Psychology. Cambridge: Cambridge University Press

Supreme Court of California (1990). Taxpayers to Limit Campaign Spending v. Fair Political Practices. Commission, 51 Cal.3d 744 . [No. S012016. Supreme Court of California. Nov 1, 1990.]

Voter Research and Surveys (1990). "Voter Research and Surveys General Election Exit Poll: State Files, 1990.” New York. Distributed by ICPSR, Ann Arbor. 


\section{Tables and figures}

\begin{tabular}{|c|c|c|c|}
\hline \multicolumn{3}{|c|}{$r>c+m$} \\
\cline { 3 - 4 } Prog. & Rad. & NY & NN \\
\hline \multirow{2}{*}{ NY } & YY & $P_{2}$ & $P_{2}$ \\
\cline { 3 - 4 } & YN & $P_{2}$ & $S Q$ \\
\cline { 3 - 4 } YY & YY & $P_{2}$ & $P_{2}$ \\
\cline { 3 - 4 } & YN & $P_{1}$ & $P_{1}$ \\
\hline
\end{tabular}

\begin{tabular}{|c|c|c|c|}
\hline \multicolumn{4}{|c|}{$r \leq c+m \leq p+r$} \\
\cline { 3 - 4 } Prog. & Rad. & NY & NN \\
\hline \multirow{2}{*}{ NY } & YY & $P_{2}$ & $P_{2}$ \\
\cline { 3 - 4 } & YN & $P_{2}$ & $S Q$ \\
\cline { 3 - 4 } & YY & $P_{2}$ & $P_{2}$ \\
\hline \multirow{2}{*}{ YY } & YY & \\
\cline { 3 - 4 } & YN & $P_{2}$ & $P_{1}$ \\
\hline
\end{tabular}

\begin{tabular}{|c|c|c|c|}
\hline \multicolumn{4}{|c|}{$c+m>p+r$} \\
\hline \multirow[b]{2}{*}{ Prog. } & \multirow[b]{2}{*}{ Rad. } & \multicolumn{2}{|c|}{ Con. } \\
\hline & & NY & $\mathbf{N N}$ \\
\hline \multirow[t]{2}{*}{ NY } & $\mathbf{Y Y}$ & $P_{2}$ & $P_{2}$ \\
\hline & $\mathbf{Y N}$ & $P_{2}$ & $S Q$ \\
\hline \multirow[t]{2}{*}{$\mathbf{Y Y}$} & $\mathbf{Y Y}$ & $P_{2}$ & $P_{2}$ \\
\hline & YN & $P_{2}$ & $S Q$ \\
\hline
\end{tabular}

Note: moderates always vote NY

Table 1: the voting game with blocs of sophisticated voters 
$\begin{array}{ll}\text { Both fail } & 8 \\ \text { Both pass } & 3 \\ & \\ \text { Original proposal only passes } & 4 \\ \text { Counter-proposal only passes } & 1\end{array}$

Table 2: Californian competing proposals, 1939-2007

Notes: where more than 2 competing proposals existed, this was only counted as one pair (all the counter-proposals always passed or failed together). Competing was defined by examining ballot pamphlets for clearly contradictory provisions and/or one proposal's supporters being the other proposal's opponents. 


\begin{tabular}{|ll|l|}
\hline Model/equilibrium & Vote pattern \\
\hline Naïve voting & $\mathrm{NN} / \mathrm{NY} / \mathrm{YN}$ \\
\hline Sophisticated voting & Moderate coalition & $\mathrm{NN}$ and NY / NY / YY and YN \\
\cline { 2 - 3 } & $\mathrm{r}>\mathrm{c}+\mathrm{m}$ & $\mathrm{NN}$ and NY / NY / YY \\
\cline { 2 - 3 } & $\mathrm{r} \leq \mathrm{c}+\mathrm{m}$, radicals compromise & $\mathrm{NN}$ and NY / NY / YY \\
\cline { 2 - 3 } $\mathrm{r} \leq \mathrm{c}+\mathrm{m}$, conservatives compromise & $\mathrm{NY} / \mathrm{YY} / \mathrm{YY}$ and YN \\
\hline
\end{tabular}

Table 3: predicted voting patterns 


\begin{tabular}{|l|l|l|l|l|l|}
\hline Election & Proposal & Sponsors & $\begin{array}{l}\text { Counter- } \\
\text { proposal }\end{array}$ & Sponsors & $\begin{array}{l}\text { Data } \\
\text { Source }\end{array}$ \\
\hline $\begin{array}{l}1988 \\
\text { General }\end{array}$ & $\begin{array}{l}\text { Proposition } \\
103\end{array}$ & $\begin{array}{l}\text { Ralph Nader, } \\
\text { consumer } \\
\text { groups }\end{array}$ & $\begin{array}{l}\text { Proposition } \\
104\end{array}$ & Auto insurers & $\begin{array}{l}\text { Field Poll } \\
88.7\end{array}$ \\
\hline $\begin{array}{l}1990 \\
\text { General }\end{array}$ & $\begin{array}{l}\text { Proposition } \\
140\end{array}$ & Republicans & $\begin{array}{l}\text { Proposition } \\
131\end{array}$ & $\begin{array}{l}\text { John Van de } \\
\text { Kamp }\end{array}$ & $\begin{array}{l}\text { VRS Exit } \\
\text { Poll }\end{array}$ \\
\hline $\begin{array}{l}1996 \\
\text { General }\end{array}$ & $\begin{array}{l}\text { Proposition } \\
216\end{array}$ & $\begin{array}{l}\text { Ralph Nader, } \\
\text { Harvey } \\
\text { Rosenfield, } \\
\text { nurses' union }\end{array}$ & $\begin{array}{l}\text { Proposition } \\
214\end{array}$ & $\begin{array}{l}\text { Doctors, } \\
\text { nurses, SEIU }\end{array}$ & $\begin{array}{l}\text { Field Poll } \\
96.6\end{array}$ \\
\hline $\begin{array}{l}2005 \\
\text { Special }\end{array}$ & $\begin{array}{l}\text { Proposition } \\
\text { Consumer } \\
\text { groups }\end{array}$ & $\begin{array}{l}\text { Proposition } \\
78\end{array}$ & $\begin{array}{l}\text { Pharmaceutical } \\
\text { companies }\end{array}$ & $\begin{array}{l}\text { Field Poll } \\
05.4\end{array}$ \\
\hline
\end{tabular}

Table 4: Competing proposals tested 


\begin{tabular}{|c|c|c|c|c|}
\hline & $\begin{array}{l}1988 \\
\text { Propositions } \\
103 \text { and } 104\end{array}$ & $\begin{array}{l}1990 \\
\text { Propositions } \\
140 \text { and } 131\end{array}$ & $\begin{array}{l}1996 \\
\text { Propositions } \\
216 \text { and } 214\end{array}$ & $\begin{array}{l}2005 \\
\text { Propositions } 79 \\
\text { and } 78\end{array}$ \\
\hline Intercept & $-0.06(0.16)$ & $0.36(0.07)^{* * *}$ & $0.95(0.42) *$ & $0.01(0.35)$ \\
\hline $\begin{array}{l}\text { Predicted logged } \\
\text { odds of Yes on } \\
\text { original }\end{array}$ & $0.16(0.19)$ & $-0.55(0.13) * * *$ & $0.75(0.29) * *$ & $-0.71(0.31) *$ \\
\hline $\begin{array}{l}\text { Voter } \\
\text { information }\end{array}$ & $\begin{array}{l}-0.56 \\
(0.08)^{* * *}\end{array}$ & -- & $0.19(0.10)$ & $-2.18(0.33) * * *$ \\
\hline AIC & 475.25 & 1539.2 & 292.62 & 435.82 \\
\hline $\mathbf{n}$ & 464 & 1176 & 216 & 353 \\
\hline Compatible with & Naïve voting & $\begin{array}{l}\text { Sophisticated } \\
\text { voting }\end{array}$ & Either & Neither \\
\hline \multicolumn{5}{|c|}{$\begin{array}{l}\text { Note: * significant at } 5 \%, * * 1 \%, * * * 0.1 \% \text {. Weighted logits. "Voter information": } 1988- \\
\text { total number of auto insurance propositions recognized; } 1996 \text { - total number of ballot } \\
\text { propositions recognized; } 2005 \text { - was voter aware of backers of both propositions? }\end{array}$} \\
\hline
\end{tabular}

Table 5: Regressions of counter-proposal vote on voter ideal point and information level among Yes voters on original proposal 


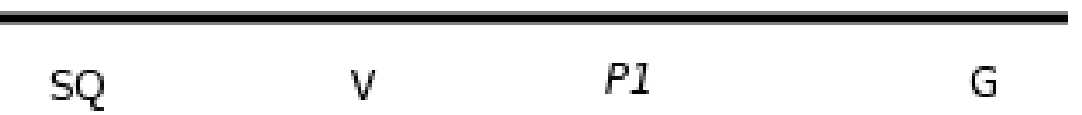

Figure 1: Simple vote choice 


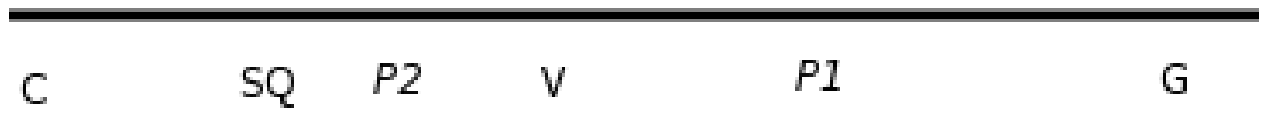

Figure 2: Complex vote choice 


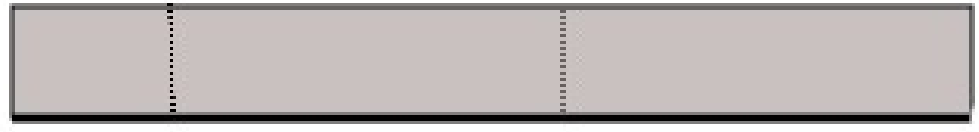

$\mathrm{SQ} \quad P 2$

P1

Figure 3: splitting naive voters with a counter-proposal. Equal numbers of voters support $P_{2}$ and $P_{l}$, so that neither proposal passes. 


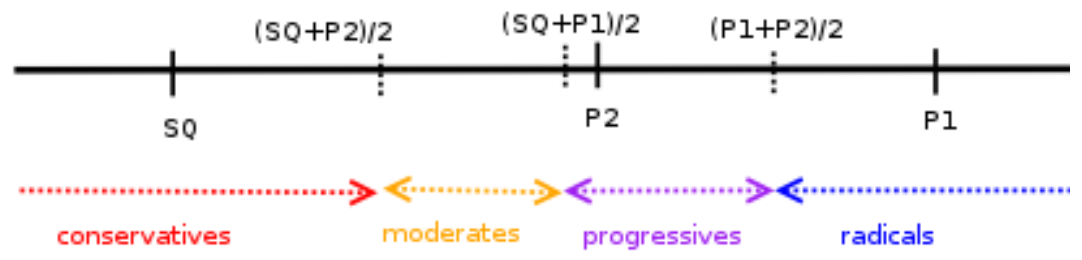

Figure 4: sophisticated voter blocs 


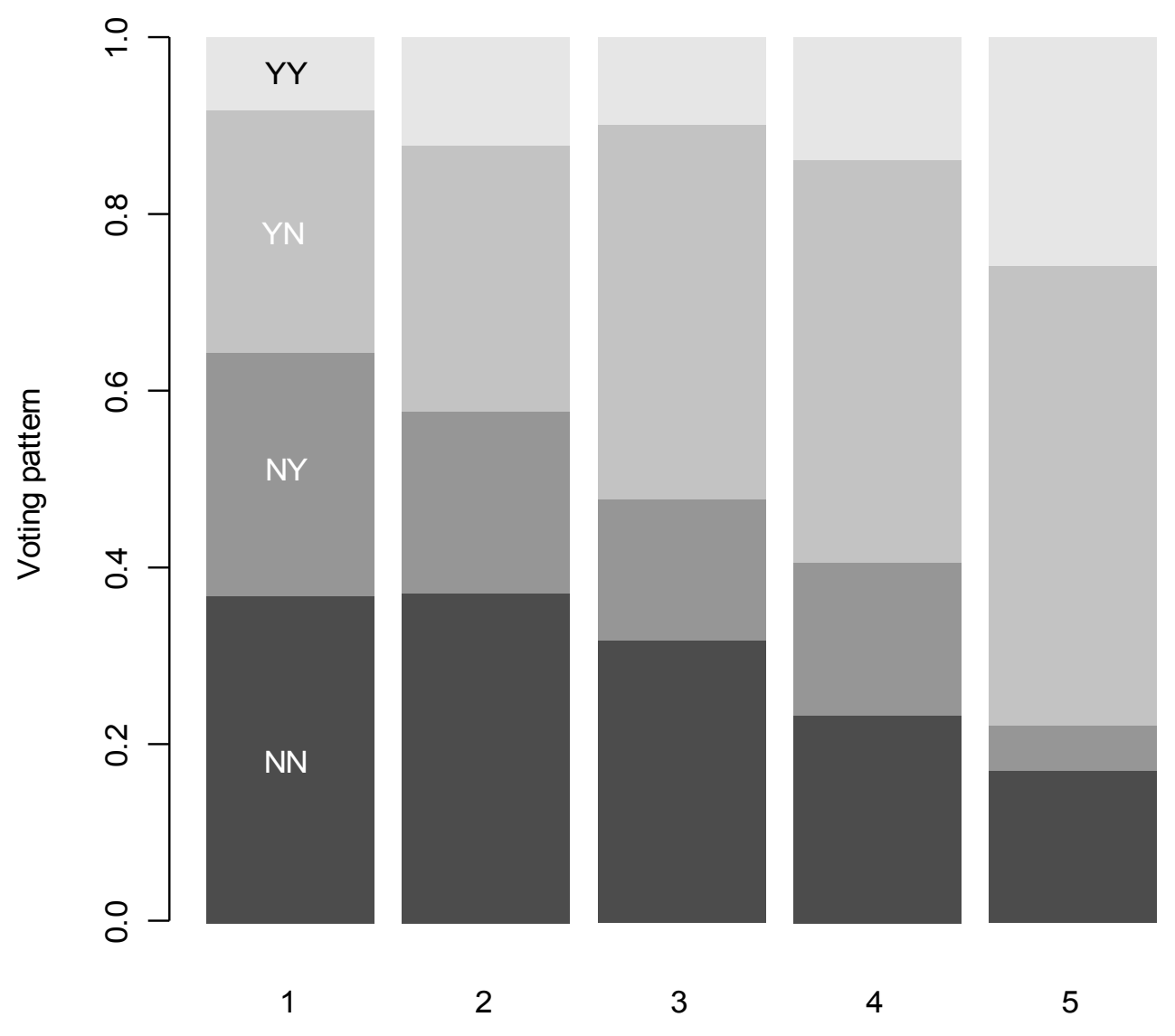

Predicted probability of Yes on 103, quintile

Figure 5: Voting patterns, Propositions 103 and 104, 1988 


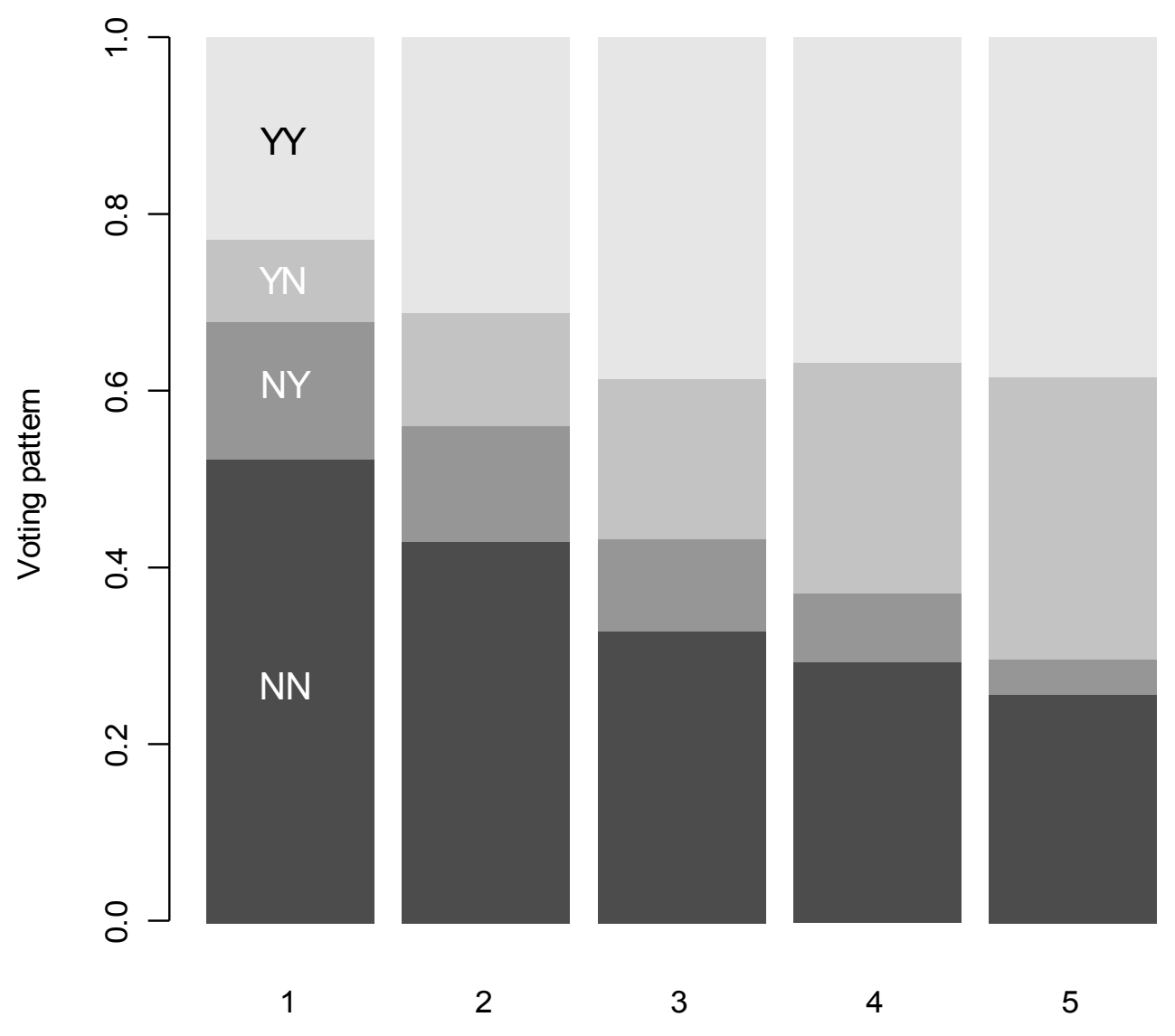

Predicted probability of Yes on 140, quintile

Figure 6: Voting patterns, Propositions 140 and 131, 1990 


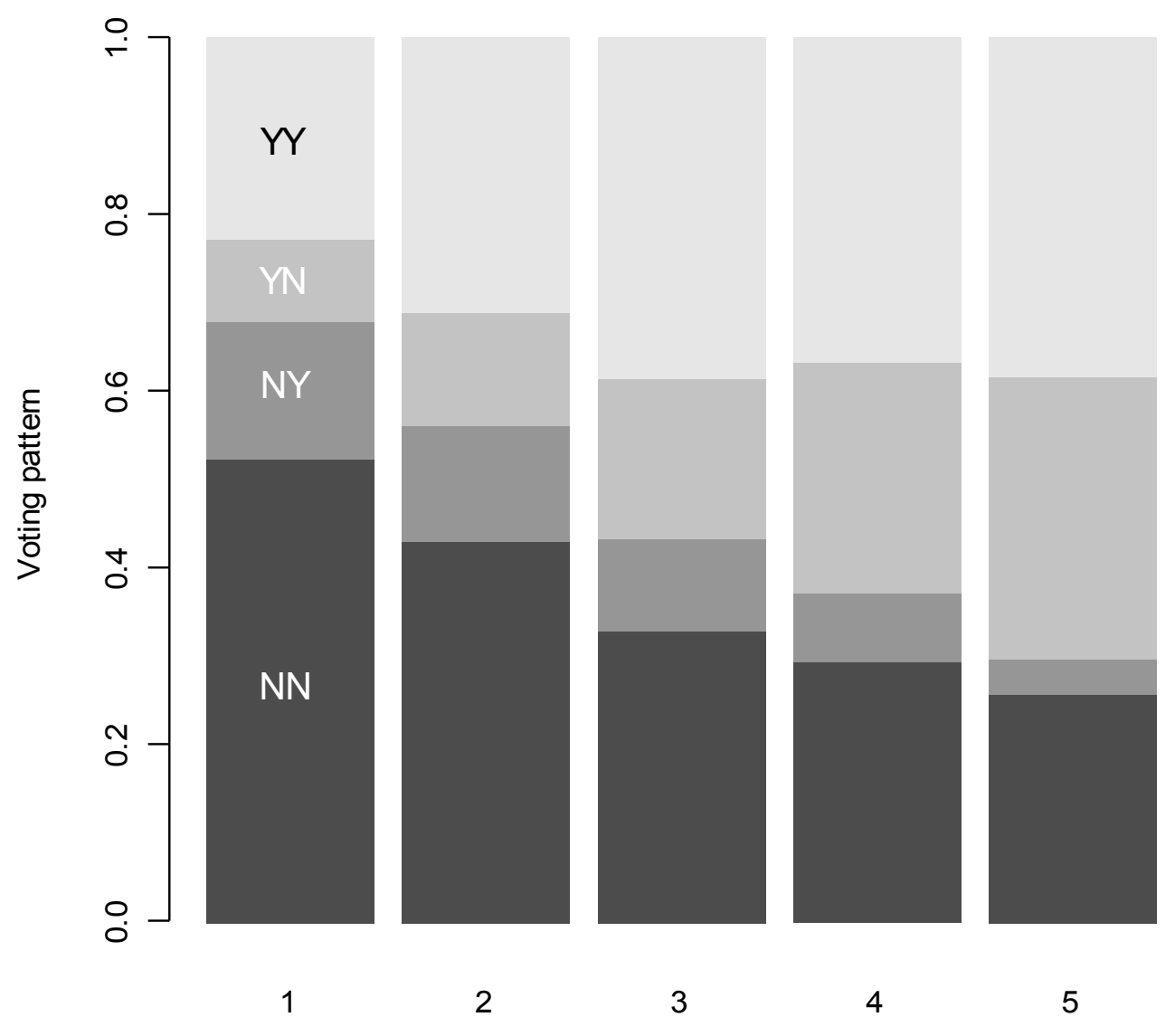

Predicted probability of Yes on 140, quintile

Figure 7: Voting patterns, Propositions 216 and 214, 1996 


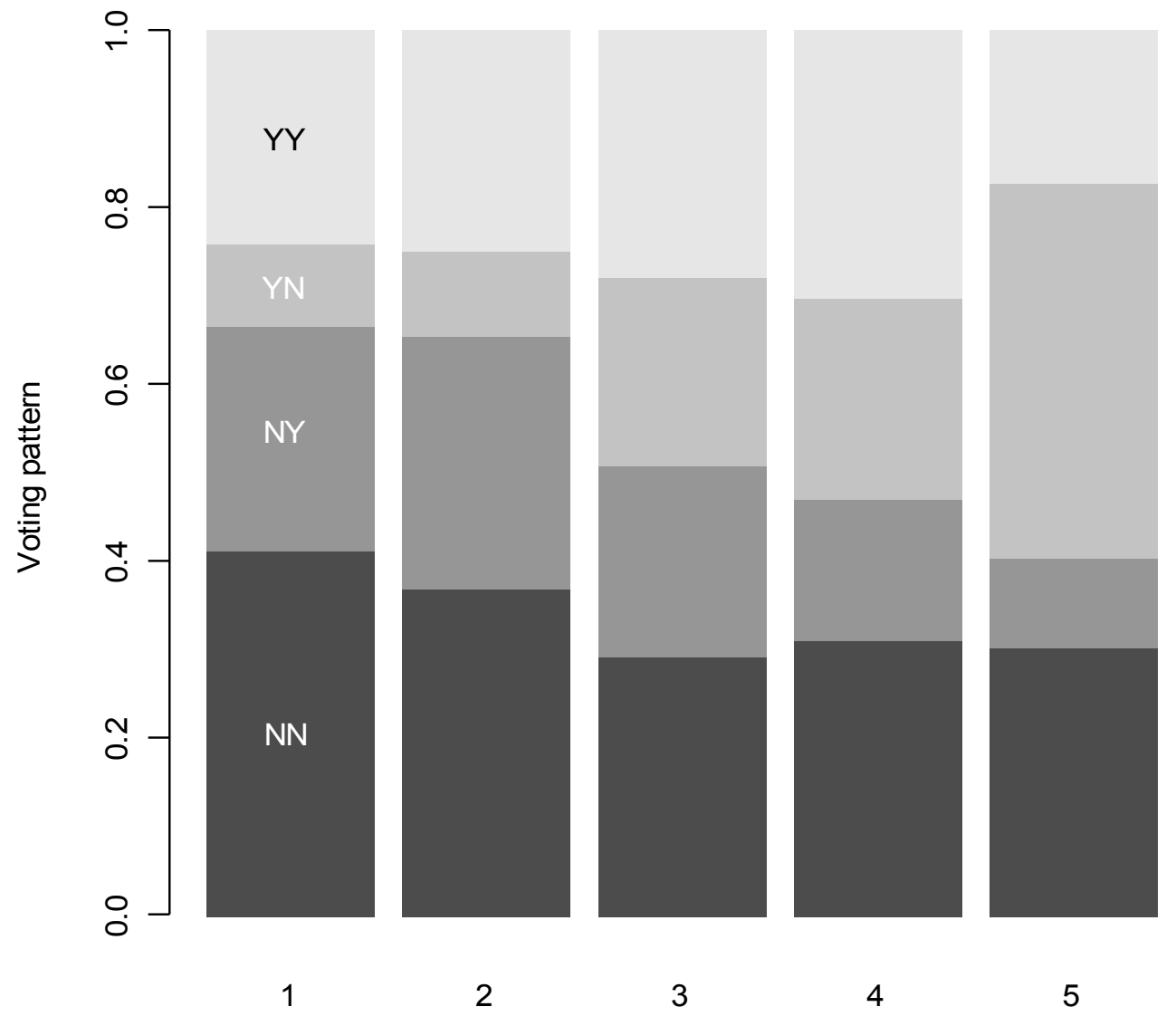

Predicted probability of Yes on 79, quintile

Figure 8: voting patterns, Propositions 79 and 78, 2005 


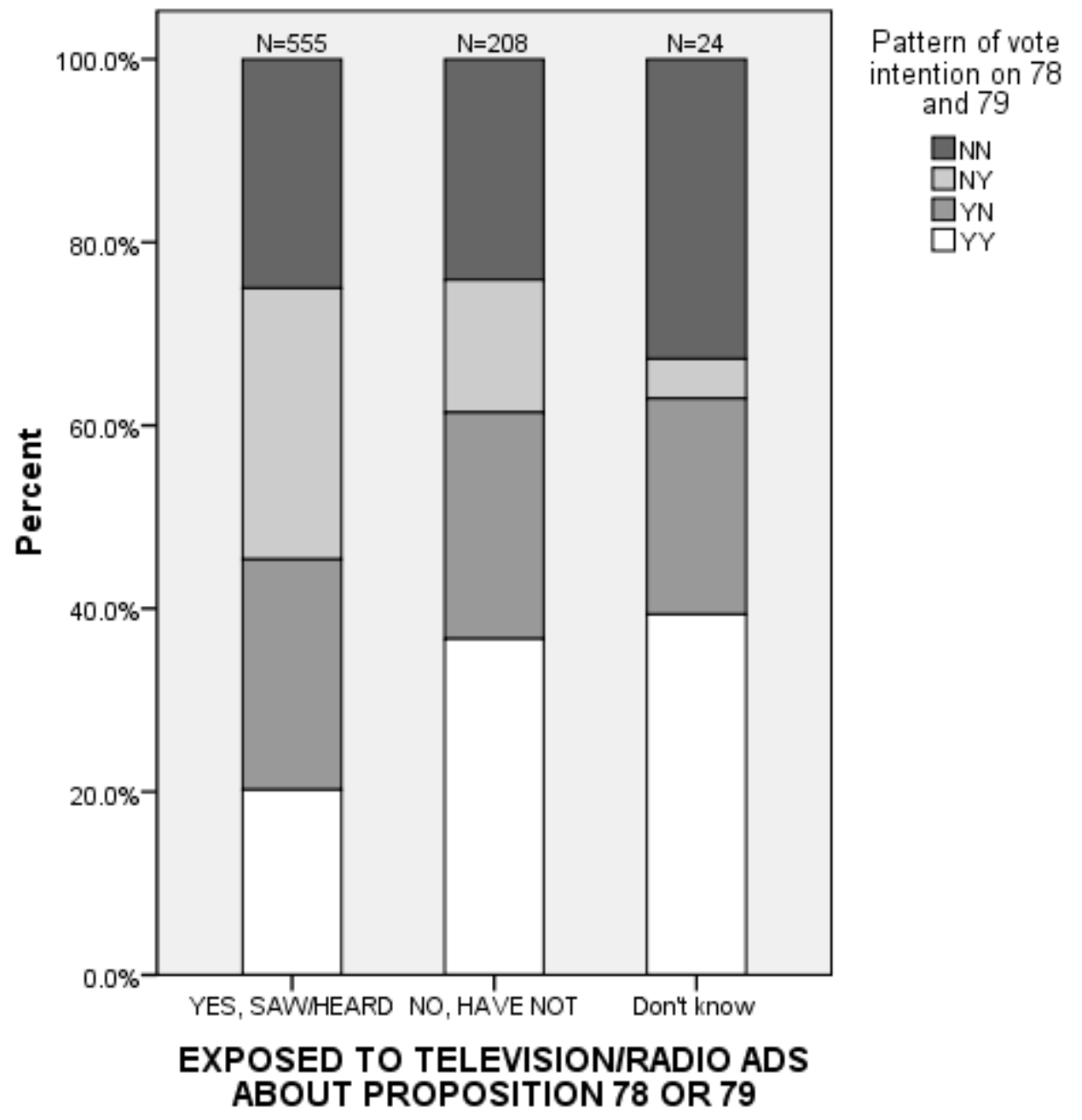

Figure 9: Voting patterns by exposure to TV ads, 2005 Propositions 78/79 